\title{
Investigación e interpretación de la música colonial latinoamericana: Pablo Hernández Balaguer, la música antigua y la Revista Musical Chilena ${ }^{1}$
}

\section{Research and performance of colonial period Latin American music: Pablo Hernández Balaguer, early music and Revista Musical Chilena}

\author{
por \\ Miriam Escudero \\ gabinete@estebansalas.ohc.cu \\ miriamescudero@gmail.com \\ Gabinete de Patrimonio Musical Esteban Salas, Oficina del \\ Historiador de la Ciudad de La Habana, Cuba
}

El musicólogo Pablo Hernández Balaguer fue el pionero de los estudios acerca del patrimonio musical cubano del período colonial. Poco o nada se conoce del desempeño de quien llegó a ser considerado el investigador más acucioso de la música cubana de los siglos XVIII y XIX. En 1956 con apenas 28 años inició y desarrolló un modelo de investigación que comprendía la localización, catalogación, transcripción y difusión del más importante y antiguo acervo de música conservado en la isla. Logró divulgar internacionalmente sus publicaciones y que la obra de Esteban Salas fuese interpretada en versión histórica, a cargo de uno de los conjuntos pioneros en la música antigua de Latinoamérica. No tuvo tiempo de terminar su obra. Antes de cumplir los 38 años le sorprendió la muerte y con ello se hizo un largo silencio en las investigaciones relativas al patrimonio musical religioso-católico cubano. Mucho ha servido su obra a los investigadores. Sea este texto un tributo a su empeño por vivir responsablemente, como si supiera que el tiempo no sería suficiente para legarnos generosamente todos sus conocimientos, y a la valiosa labor de la Revista Musical Chilena que siempre ha difundido los resultados de nosotros los latinoamericanos.

Palabras clave: patrimonio musical cubano, música antigua, Revista Musical Chilena

The musicologist Pablo Hernández Balaguer pioneered the studies of the Cuban musical heritage in the colonial period. Little or nothing is known about the activity of a man who came to be considered as the most careful scholar of Cuban music of the 18th and 19th centuries. In 1956, when he was only 28 years old, he started and developed a research model that included actions like locating, classifying, transcribing and diffusion of the most important

1 El presente trabajo constituye uno de los resultados del proyecto de investigación titulado $\mathrm{El}$ patrimonio histórico-musical de las catedrales e iglesias de Cuba que dirige la Dra. Miriam Escudero y en el que participan el Gabinete de Patrimonio Musical Esteban Salas de la Oficina del Historiador de la Ciudad de La Habana, el Centro de Investigación y Desarrollo de la Música Cubana y la Universidad de Valladolid, España. 
and ancient heritage of music preserved in the Island. Balaguer achieved to disseminate internationally his publications and the musical work of Esteban Salas, that was first performed in a historical version by one of the pioneer ensembles in the early music movement in Latin America. However he did not have time to finish his work. He died before reaching his $38^{\text {th }}$ birthday. Thereafter a long interruption came about in the research pertaining the Cuban catholic religious musical heritage. His work has been a great assistance to many scholars. This paper is a tribute to his determination to live conscientiously as if he had known that he did not have enough time to generously transmit his knowledge to the younger generations. Its is also a tribute to the valuable effort of the Revista Musical Chilena to communicate the results of the research carried out by Latin American scholars.

Key words: Cuban musical heritage, early music, Revista Musical Chilena

"Algunas personas han escrito sobre Salas y su importancia artística; nosotros, además, hemos considerado que no solo literatura sobre su música podía rescatarla verídicamente” (Hernández Balaguer 1986a: 90)

El musicólogo cubano Pablo Hernández Balaguer se hubiera sentido agradecido de poder asistir al más reciente Festival de Música Renacentista y Barroca Americana Misiones de Chiquitos en Bolivia porque al día de hoy se trata de "la experiencia" imprescindible para conocer lo más esencial de Latinoamérica en materia de música antigua o música históricamente informada, como se denomina académicamente a esa filosofía de la interpretación. Allí, en la antigua misión de Santa Ana, podría constatar que una tradición cultural impuesta puede ser aprehendida y redimensionada hasta hacerse propia y que hoy los límites entre lo autóctono, lo auténtico y lo importado se han desvanecido.

La propuesta de estrategias para el rescate y difusión del patrimonio musical de Latinoamérica tiene una historia parcialmente desconocida de actores locales como Pablo Hernández Balaguer (La Habana, 13 de julio de 1928-31 de enero de 1966), quien fue uno de sus máximos exponentes en Cuba. Varios estudiosos como Alejo Carpentier (La Habana, 1904-París, 1980) e Hilario González (La Habana, 1920-1996) recorrieron el camino de la investigación del más antiguo patrimonio musical cubano, pero solo Balaguer logró desarrollar en unos escasos diez años un intenso programa que abarcó desde la localización del documento hasta la difusión del hecho musical y su internacionalización en el incipiente movimiento de música antigua de su época. En la Universidad de Oriente, en Cuba, se conserva una parte de la valiosa correspondencia inédita remitida a él en relación con su trayectoria profesional. Lamentablemente no hemos hallado aún la correspondencia enviada, así que serán esas fuentes primarias y sus trabajos los que nos permitirán caracterizar la dimensión de su labor pionera.

El propio Hernández Balaguer confiesa que llegó a Santiago de Cuba a partir de octubre de 1956 con el propósito de "buscar pacientemente en el Archivo de Música de la Catedral de Santiago, a fin de rescatar cuanta obra de Salas y de otros compositores cubanos pudiese guardar" (Hernández Balaguer 1961d: 5). Y es que una vez localizada por Carpentier la obra de Esteban Salas y difundida la noticia del hallazgo del más importante reservorio de partituras del país en su antológico libro La música en Cuba (1989), Balaguer comprendió que el Archivo de la Catedral de Santiago de Cuba era un fondo peculiar e inexplorado. Así decidió aproximarse a su estudio desde la perspectiva de la función a la que había estado destinada esa música. 
En carta de Monseñor Raúl del Valle, Secretario de Cámara de Su Eminencia Monseñor Manuel Cardenal Arteaga y Betancourt, Arzobispo de La Habana, fechada el 6 de enero de 1957, se explica esa intención:

"Por este medio se recomienda muy encarecidamente ante los reverendos señores Curas Párrocos y Directores de Archivos y Bibliotecas eclesiásticas de Cuba al profesor Pablo Hernández Balaguer, de la Facultad de Música de la Universidad de Oriente, y al profesor Odilio Urfé, Director del Instituto Musical de Investigaciones Folklóricas, que se encuentran realizando estudios de investigación sobre la música sacra en Cuba. Los profesores Pablo Hernández Balaguer y Odilio Urfé han sido recomendados ante este Arzobispado por el Señor Presbítero Ángel Gaztelu, Párroco de la Iglesia del Espíritu Santo de esta ciudad"2.

Ese énfasis en los "estudios de investigación sobre la música sacra en Cuba", quizás se sustentara en el hecho de que quien recomendaba a Balaguer y a Urfé era el padre Gaztelu, activo miembro del grupo Orígenes quien junto a José Lezama Lima, Cintio Vitier y Fina García Marruz habían defendido las esencias de la cubanía en el patrimonio cultural cubano de origen hispánico y católico. Otra había sido la intención de Carpentier en su libro de 1946, quien ponderaba por encima de la labor pastoral de Salas y de su vínculo con la iglesia el hecho de tratarse del primer músico cubano del que se conservaban documentos musicales:

"No acertamos a explicarnos [comenta Carpentier en su libro] cómo la obra y la personalidad de Esteban Salas han permanecido en la más absoluta obscuridad. No se le menciona, siquiera, en los libros que han sentado cátedra y se estudian en los conservatorios por recomendación oficial. No aparece su nombre en ningún diccionario biográfico cubano. [...] Sin embargo, por la importancia del papel desempeñado en la historia de la música cubana, Salas era, sin duda alguna, el personaje que se hacía más merecedor de una acuciosa investigación" (Carpentier 1989: 66).

Carpentier perseguía en este caso el estudio de la figura individual, la exaltación del sentido de identidad desde el siglo XVIII con la búsqueda de artistas e intelectuales que validaran la presencia nacionalista del criollo. Convirtió a Esteban Salas en el primer "ícono de la gesta musical cubana", lo homologó con algunos maestros venezolanos y enfatizó que el hallazgo de su obra:

“[...] venía a completar nuestra visión de la música religiosa americana, en un momento [se refiere al siglo XVIII] en que, por haber sido mal estudiado, pudo parecer pobre en actividades creadoras, cuando constituyó en realidad una de las etapas más interesantes y ricas en la producción artística del Nuevo Mundo. Salas [abunda] era bastante más que el honesto presbítero americano [...], que considera su función de maestro de capilla como una especie de cargo burocrático y compone música sacra de acuerdo con las reglas aprendidas [...]. Este compositor fue el verdadero punto de partida de la música seria en Cuba". (Carpentier 1989: 66-67).

2 Carta de recomendación del Arzobispado de La Habana, La Habana, 6 de enero de 1957, SUO (Santiago de Cuba, Universidad de Oriente), expediente sin número (exp. s/n.). 
Por su parte el músico Odilio Urfé González (La Habana, 1921-1988), al que también menciona la carta de recomendación del obispo, había creado en 1949 el Instituto Musical de Investigaciones Folklóricas (IMIF) con sede permanente, desde 1956, en la Antigua Iglesia de San Francisco de Paula, inmueble cedido por acuerdo con la Junta Nacional de Arqueología y Etnología y por intermedio del historiador de La Habana Emilio Roig de Leuchsenring (actualmente sede del Conjunto de Música Antigua Ars Longa) para acoger el museo y archivo de esa institución. Se trataba del primer centro de documentación musical con perspectiva científica que se creaba en Cuba y que además de fomentar uno de los más importantes fondos documentales de la época, fue la primera sala de conciertos, exposiciones y conferencias que vinculaba las tareas de investigación e interpretación. Desde su acta de fundación defendía su labor pública con un claro y vehemente propósito: "Rescatar, recopilar, clasificar, estudiar, difundir y defender toda manifestación propia del patrimonio de la cultura musical cubana, sin discriminación de clase alguna, aunque poniéndose énfasis en todo lo referente a las expresiones de raíz popular" (Gómez Cairo 1989: 7-10). Como tarea prioritaria llevó a cabo la compilación de una colección completa de instrumentos típicos de la música cubana, así como de partituras originales de compositores cubanos de todos los géneros populares y de concierto, del cancionero patriótico, amoroso y bucólico. Incluía, además, fotografías, grabados, programas, carnés de baile del siglo XIX, revistas, etc. A partir de esos fondos patrimoniales se realizaron numerosos recitales, exposiciones de pintura y la presentación con regularidad de la Charanga Nacional de Conciertos $^{3}$. Previo a su sede en la Iglesia de Paula, ya el IMIF había organizado eventos como el Primer Festival de Música Folklórica (1953) y el Primer Concurso Nacional de Danzones (1954). Esa relación investigación-interpretación, aunque en el ámbito de la música popular, fue un importante modelo para Balaguer, quien mantenía un estrecho vínculo con el maestro Urfé:

"Por Prats, el arqueólogo [escribe Urfé], supe que no habías abandonado los trabajos de investigación. No obstante la conversación que sostuve con él, no pude colegir en qué grado se encuentran las mismas. ¿Encontraste la tumba del Padre Salas? ¿Hiciste el catálogo completo del Archivo de la Catedral? ¿Qué datos y partituras interesantes encontraste? [...] Debo anunciarte que para cuando vengas por acá, ojalá sea pronto, espero tener aquí, debidamente instalado, un Órgano que he conseguido con el Instituto Nacional de Cultura. Como verás, ya contamos con el elemento principal para organizar y efectuar los conciertos de música sacra interamericana con base en la obra de Salas, París, Rafelín, Pujals, Guerra y otros músicos cubanos o nacionalizados”"4.

3 "Tipo de agrupación llamada también (charanga) francesa. Surge en los primeros años del siglo XX, como derivación de la orquesta típica o de viento. Interpreta principalmente danzones, aunque a partir de la irrupción del chachachá (1951) es vehículo idóneo para este nuevo género. Originalmente estuvo formada por flauta, violín, piano, contrabajo, timbal o paila criolla, y güiro; se le ha incorporado la tumbadora, otros dos violines y tres cantantes" (Orovio 1992:114-115).

4 Carta de Odilio Urfé a Pablo Hernández Balaguer, La Habana, 26 de junio de 1958, SUO, exp. s/n. 
Es decir, Urfé conocía los progresos de Balaguer de llevar adelante las primeras tareas de investigación-interpretación y estaba dispuesto a apoyarle en La Habana. Esas tareas abarcaban la confección de un catálogo del Archivo de la Catedral de Santiago de Cuba, el estudio de las obras más relevantes y la difusión de esas obras como exponentes de la "música sacra interamericana". Esta última denominación estaba en consonancia con los postulados de Orígenes, entendida la catolicidad como ecumenismo y universalidad, que según Cintio Vitier "ha sido siempre aspiración de lo cubano mejor"5 y también con el libro La música religiosa en Cuba de María Maciá de Casteleiro publicado en 1956 como primera historia contextualizada de la creación musical para el culto católico. Y es más, posiblemente la relación entre Urfé y Balaguer condicionó ese plan de trabajo puesto que Urfé, como director del Instituto Musical de Investigaciones Folklóricas, podía aportar experiencia al joven musicólogo que por entonces tenía solo 30 años.

Es con el triunfo de la Revolución Cubana, en enero de 1959, que se crean las condiciones propicias para llevar adelante los propósitos que Balaguer había compartido con Urfé. En un artículo publicado en el periódico Revolución, el 27 de abril de 1959, escribe:

"Si algo no podemos nunca dejar de agradecer suficientemente a la Revolución es la reconquista de la fe nacional, de la fe en las propias dignidad y capacidad, por lo cual estimamos que en este momento extraordinario que nos toca vivir debemos aunar esfuerzos y hacer posible que la divulgación y conservación de nuestra música presente y pasada sea una realidad. Es ahora el momento oportuno para la creación de un Archivo Histórico de Música, que comprenda todos los capítulos de especialidades: folklórico, sinfónico, religioso, etc. y que tenga filiales en todo el territorio nacional" (Hernández Balaguer 1959).

La década de los años sesenta en Cuba fue un momento de esplendor para la intelectualidad cubana pues en las principales instituciones de la cultura se colocaron personalidades de gran prestigio profesional tanto nacional como internacional: José Antonio Portuondo (Santiago de Cuba, 1911-La Habana, 1996), profesor, crítico, ensayista e historiador literario era el rector de la Universidad de Oriente; el arqueólogo Francisco Prat Puig (La Pobla de Lillet, Cataluña, 1906-Santiago de Cuba, 1997) era el decano de la Facultad de Humanidades; María Teresa Freyre de Andrade (San Agustín de la Florida, 1896-La Habana, 1975), máxima autoridad de la escuela de bibliotecología cubana, dirigía la Biblioteca Nacional de Cuba y Argeliers León (La Habana, 1918-1991), el fundador de la escuela de musicología en Cuba, que había sido discípulo de don Fernando Ortiz, estaba al frente de su Departamento de Música; el compositor José Ardévol (Barcelona, 1911-La Habana, 1981) presidía el Consejo Nacional de Cultura de Cuba; Julio Le Riverand (La Coruña, 1912-La Habana, 1998), historiador y experto en estudios

5 Entrevista a Cintio Vitier, publicada bajo el título "La memoria compartida", en revista Opus Habana, I/2 (enero-marzo, 1997), p.16 [pp. 14-27]. 
sobre la economía cubana del siglo XIX conducía los destinos del Archivo Nacional de Cuba. Con todos ellos Balaguer mantuvo correspondencia y recibió el apoyo incondicional para sus proyectos.

Para llevar adelante sus propósitos Balaguer debió crear una metodología de trabajo con sede en la Universidad de Oriente, primer centro que introdujo la enseñanza de la música en Cuba en el nivel superior. En un trabajo publicado en una compilación de artículos suyos resalta:

"El trabajo de investigación musicológica que se viene realizando por parte de la Sección de Música de la Universidad de Oriente no se ha limitado a la búsqueda y estudio de las obras musicales, sino que comprende también el sondeo de los archivos en todo aquello que pueda tener relación con la música, en especial documentos que puedan contener datos relativos a la vida y actividad musical de los compositores estudiados, como son las actas de ordenación, capitulares, reales cédulas, etc. a más de partidas de bautismo, defunciones, y otros documentos por el estilo" (Hernández Balaguer 1986a: 212).

Planteaba así el método de investigación musicológico con énfasis en el uso de las fuentes documentales como herramienta para la construcción de un tipo de discurso sobre el pasado. En sendas cartas de 5 de mayo de 1960 Balaguer recibió la autorización de la Iglesia en Santiago de Cuba de parte de Monseñor Enrique Pérez Serantes, Arzobispo de esa ciudad, tanto "para investigar en el Archivo de Música Sagrada de Nuestra Santa Metropolitana Iglesia Catedral en orden a la publicación de las Obras completas del Maestro Pbro. Esteban Salas que va a hacer la Universidad de Oriente" como para "inscribir en el Registro de la Propiedad Intelectual la Edición de las obras Completas del Pbro. Esteban Salas" ${ }^{6}$ con lo cual también contaba con el apoyo incondicional de la Iglesia Católica cubana.

Los primeros resultados de la labor de Pablo Hernández Balaguer en Santiago de Cuba ponen en evidencia la efectividad de los vínculos con las instituciones académicas y religiosas, pero sobre todo destaca su perspectiva metódica que privilegia el estudio de la partitura como una fuente histórica en sí misma y la necesidad del análisis del contexto en la historia musical. Entonces, a partir de 1960 inicia una especie de carrera desenfrenada por publicar y difundir todo el conocimiento que había adquirido.

Produce junto a Miguel García (La Habana, 1926-1981), director del Coro de Madrigalistas de Santiago de Cuba, tres conciertos con música de Esteban Salas, uno en la Catedral de Santiago de Cuba (28 de febrero) y otros dos en La Habana (12 y 13 de abril), estos últimos con sendas presentaciones de Alejo Carpentier. De ellos derivó el programa del primer disco de vinilo titulado Esteban Salas y dedicado íntegramente a difundir la obra del más antiguo compositor cubano del que se conservan partituras en la isla, que fuera grabado por la Universidad de Oriente y la Sección de música del Departamento de actividades culturales.

6 Cartas del Arzobispo Monseñor Enrique Pérez Serantes a Pablo Hernández Balaguer, Santiago de Cuba, 5 de mayo de 1960, SUO, exp. s/n. 
El disco se acompaña de un "folleto complementario": Obras de Esteban Salas y un ensayo de Pablo Hernández Balaguer, también a cargo de la Universidad de Oriente, que no es más que la nota crítica de ese primer concierto ofrecido en la Catedral de Santiago de Cuba el 28 de febrero de 1960 (Hernández Balaguer 1960a).

Difunde su artículo "En torno a los villancicos de Esteban Salas" en un soporte especializado como el de la Revista de Música de la Biblioteca Nacional José Martí, en La Habana, fundada y dirigida por Argeliers León. Se trata de un análisis musical dedicado al repertorio no litúrgico de Salas en el que Balaguer ubica el género en la tradición española y caracteriza musicalmente las obras que ha logrado compilar, pero le faltan los referentes de otros compositores latinoamericanos. Además escribe este texto en medio de los trabajos de catalogación y no conoce aún todas las obras de Salas. Para mantener la altura del lugar que ha otorgado Carpentier a Salas como "primer clásico cubano", Balaguer afirma que sobre "la cubanía de los Villancicos de Esteban Salas, cabría decir [...] que fueron ejecutados en un sentido diverso a como lo hubieran sido en España", pero no aporta aun las razones musicales de ese comportamiento que más contemporáneamente será denominado "criollismo" (Hernández Balaguer 1960b).

También a instancias de Argeliers León, director del Departamento de Música de la Biblioteca Nacional de Cuba, Balaguer culmina en 1961 su obra magna, el Catálogo de música de los archivos de la Catedral de Santiago de Cuba y del Museo Bacardí. Publica además las primeras transcripciones de composiciones de Esteban Salas en el libro Cuatro villancicos que contiene las obras: Respirad, o mortales, Los bronces se enternescan, Toquen presto a fuego, y ¡Tú mi Dios entre pajas! (Hernández Balaguer 1961c). Argeliers León y Pablo Hernández Balaguer mantenían una relación cordial de mentor y discípulo. Argeliers, quien años más tarde será el fundador del Departamento de Musicología en el Instituto Superior de Arte, asesora sus trabajos con la certeza de que constituían una importante contribución al establecimiento de pautas para los estudios científicos de la música en $\mathrm{Cuba}$. $\mathrm{Al}$ respecto afirmaba en el prólogo al Catálogo:

"La ausencia de bases conceptuales en los estudios musicales, la ausencia de medios de investigación, la ausencia de materiales documentales, la ausencia de la música de los cubanos en la vigencia sonora de nuestro pueblo [...] requiere integrar esfuerzos colectivamente para fundar en nuestra Patria unas normas serias para el estudio de la música” (Prólogo al Catálogo de música... Hernández Balaguer 1961a).

Ese mismo año de 1961 aparecen una tras otra las primeras ediciones facsimilares de las obras más representativas del Archivo de la Catedral de Santiago de Cuba y el Museo Bacardí. En ese formato el Departamento de actividades culturales de la Universidad de Oriente publica el villancico Claras luces, a cuatro voces con violines y bajo de Esteban Salas (Hernández Balaguer 1961b) y la Misa en do mayor para tres voces y orquesta de Cratilio Guerra (Hernández Balaguer 1961e). Por su parte el Consejo Provincial de Cultura de Santiago de Cuba edita la Primera lección de difuntos de Silvano Boudet (Hernández Balaguer 1961f).

Inmediatamente se inicia la difusión internacional de las obras impresas del Archivo de Música de la Universidad de Oriente. Pablo Hernández Balaguer envía 
las partituras a diferentes centros. El primer destino fue la Exposición Histórica Cubana en Checoslovaquia de 1961, por encargo del director de asuntos culturales del Ministerio de Relaciones Exteriores de Cuba, que había solicitado el folleto y el disco dedicado a Esteban Salas ${ }^{7}$. Ese mismo año Balaguer comparte sus publicaciones con Andrés Pardo Tovar (Bogotá, 1911-1972), director del Centro de Estudios Folclóricos y Musicales de la Universidad Nacional de Colombia lo que le vale el nombramiento de Miembro Honorario de esa institución ${ }^{8}$.

\section{PANORAMA DE LA MÚSICA COLONIAL CUBANA}

En el caso de la Revista Musical Chilena, la relación entre esta prestigiosa institución y Pablo Hernández Balaguer se establece a partir de una recomendación hecha por el compositor Roque Cordero (Panamá, 1917-Dayton, Ohio, 2008), quien presenta a Balaguer como "la persona idónea para ayudarnos en su patria" . El primer contacto se inició con el envío de las publicaciones de música de la Universidad de Oriente a las Bibliotecas de la entonces Facultad de Ciencias y Artes Musicales de la Universidad de Chile, entre ellas: villancicos, canciones latinoamericanas, la Misa de Cratilio Guerra, las obras de Silvano Boudet y Rodolfo Hernández, y el disco de Esteban Salas ${ }^{10}$.

En el entorno de la musicología latinoamericana era la época del descubrimiento del patrimonio musical del Nuevo Mundo y, lo más importante, los responsables de cada institución eran hombres y mujeres ilustrados, con un alto aprecio por el intangible valor de la cultura. Pablo Hernández Balaguer, que había adquirido ya seguridad con maestros de la talla de Argeliers León y Odilio Urfé, propone a la Revista Musical Chilena un artículo sobre la música colonial en Cuba en los siglos XVI al XVIII. Su sugerencia fue aceptada con entusiasmo para ser insertado en un "número colonial"11. El artículo "Panorama de la música colonial cubana” se incluyó en el número 81-82 de la Revista Musical Chilena publicada entre julio y diciembre de 1962. Su contribución fue colocada junto a otros estudios relativos al mismo período y entre los más importantes especialistas del momento.

7 Carta de Lázaro Vigoa, director de Asuntos Culturales del Ministerio de Relaciones Exteriores de Cuba, La Habana, 3 de marzo de 1961, SUO, exp. s/n.

8 Cartas de Andrés Pardo Tovar, director del Centro de Estudios Folclóricos y Musicales de la Universidad Nacional de Colombia a Pablo Hernández Balaguer, Bogotá, 18 de marzo y 22 de agosto de 1961, SUO, exp. s/n.

9 Carta de Magdalena Vicuña, redactora jefe de la Revista Musical Chilena, a Pablo Hernández Balaguer, Santiago de Chile, 29 de agosto de 1961, SUO, exp. s/n.

10 Carta de Magdalena Vicuña, redactora jefe de la Revista Musical Chilena, a Miguel García, director de la sección de música de la Universidad de Oriente, Santiago de Chile, 22 de enero de 1962, SUO, exp. s/n.

11 Carta de Magdalena Vicuña, redactora jefe de la Revista Musical Chilena, a Miguel García, director de la sección de música de la Universidad de Oriente, Santiago de Chile, de 17 de abril de 1962, SUO, exp. s/n. Cf. A este respecto de Luis Merino Montero, "Editorial", Revista Musical Chilena, LXVII/219 (enero-junio, 2013), pp. 10-11. 


\section{AÑO XVI Santiago de Chile, Julio-Diciembre de $1962 \quad$ N.os 81-82}

\section{R E S U M E N}

EDITORIAL $\quad . \quad$.
ANDRES SAS: La vida musical en la Catedral de Lima durante la colonia

Se trata de un estudio preliminar en el que Balaguer afirma al comienzo que la documentación sobre los siglos XVI y XVII aporta pocas noticias e inicia su relato a partir de la figura de Esteban Salas. Luego hace una breve mención a Juan París (sucesor de Esteban Salas, que fue maestro de capilla de la Catedral de Santiago de Cuba entre 1805 y 1845), sin desarrollo alguno y continúa con los aspectos más relevantes de la composición de músicos criollos del siglo XIX. No hace citas bibliográficas, se apoya únicamente en su criterio de autoridad y plantea un panorama general de los resultados de sus primeros trabajos. No obstante, sobre el impacto que este número de la Revista Musical Chilena tuvo para los estudios sobre música colonial hispanoamericana comenta la investigadora Juliana Pérez:

"En la década de 1960 se hizo notorio el empuje que desde la anterior venían teniendo los estudios sobre música colonial [...] es significativo el reconocimiento del tema que hizo en 1962 la Revista Musical Chilena, dedicando el número 81-82 a los trabajos de vanguardia de grandes figuras como Lauro Ayestarán, José Antonio Calcaño, Vicente Gesualdo, Pablo Hernández Balaguer, Andrés Sas, Robert Stevenson y Carlos Vega" (Pérez 2004: 285).

Ese mismo texto de Balaguer, ampliado hasta el siglo XX, fue publicado posteriormente en Cuba en la Revista Bohemia, en tres entregas, en los números de 21, 28 de agosto y 4 de septiembre de 1964 y reeditado en un texto titulado Breve historia de la música cubana, publicado por la Universidad de Oriente (1964b).

\section{LOS VILLANCICOS, CANTADAS Y PASTORELAS DE ESTEBAN SALAS}

Una vez localizadas las obras y comprendido el alcance de la música del período colonial en Cuba, Pablo Hernández Balaguer centra todos sus esfuerzos en la 
creación musical de Esteban Salas, músico al que considera el más representativo de los fondos que estudia. Ya en septiembre de 1961 afirmaba que:

"La música litúrgica de Salas ha permanecido ignorada desde que dejó de tocarse a fines del siglo pasado. Por este motivo, en los conciertos primeros que dimos con su música nos preocupamos de que ella estuviese dignamente representada. El desconocimiento de esta parte considerable de su obra ha creado un pequeño prejuicio en torno a todo aquello que no sean sus Villancicos. Tal cosa carece por completo de verdadero fundamento, porque la calidad de su obra litúrgica es extraordinaria y aunque permanece desconocida [a excepción de algunas obras] auguramos que no lo será por mucho más tiempo" (Hernández Balaguer 1961d:5).

Así al año siguiente, en 1962, la Universidad de Oriente publica su libro 3 obras litúrgicas, primero en Cuba que contiene las transcripciones de un repertorio de este tipo (1962b).

El 9 de abril de 1962 detalla el ambicioso plan de trabajo que debe llevar a cabo la Sección de Investigaciones del Departamento de Investigaciones y Extensión Musical de la Escuela de Historia en la Universidad de Oriente:

"Primero.- Abordar la publicación del primer tomo de las obras completas de Esteban Salas, el cual contendrá los villancicos, cantadas y pastorelas de este compositor que se conservan en el Archivo de Música de esta Universidad.

Segundo.- El contenido de este tomo en cuanto a estudio sobre los mismos será el siguiente:

$\underline{\text { Los Villancicos, cantadas y pastorelas de Esteban Salas }}$

Antecedentes históricos

Vida de Esteban Salas

Las voces que emplea en estas obras

La instrumentación

La tonalidad

La forma

La escritura

El estilo

Vínculos con la tradición musical española

Presencia de elementos folklóricos hispanos

Conclusiones" 12 .

A partir del tercer punto en adelante, describe el procedimiento para la transcripción de las partituras que han de publicarse de conjunto con el estudio teórico propuesto:

"Tercero.- El número de villancicos, cantadas y pastorelas de Salas que conservamos en el Archivo de Música de la Universidad, alcanza la cifra de 46. De estas 46 obras ya transcritas a notación moderna 7 , las cuales serán sometidas nuevamente a revisión.

12 Plan de trabajo de la Sección de Investigaciones del Departamento de Investigaciones y Extensión Musical presentado por Pablo Hernández Balaguer, Responsable de la Sección de Investigaciones, Santiago de Cuba, 9 de abril de 1962, SUO, exp. s/n. 
Quinto.- A esta tarea de transcripción y restauración que ha de situar todas estas obras en disposición de ser copiadas en limpio y a tinta como corresponde, para su publicación, se unirá la labor de recopilación como continuación a lo ya realizado en este sentido. Sexto.- Como labor de recopilación se entiende: datos biográficos; estudio de partituras de diversos compositores de los siglos XVII y XVIII a fin de extraer similitudes y diferencias con la obra de Salas, en especial, villancicos en todas sus formas; selección y estudio de las actas capitulares de la catedral de Santiago de Cuba y otros documentos relacionados con nuestro trabajo".

Balaguer explica su procedimiento de transcribir la música y conocer así la obra para poder contextualizarla en su entorno local y caracterizarla estilísticamente en el entorno y proyección histórica de la época. Un año más tarde, el 20 de noviembre de 1963, presenta un nuevo informe a la Comisión de Publicaciones de la Universidad de Oriente. Está consciente de que, ante la urgencia de terminar esta obra, tendrá que obviar la publicación de las partituras y privilegia solo el contenido teórico argumentando que: "El libro, cuyo cuerpo principal es el análisis musical de cada uno de los 51 Villancicos, Cantadas y Pastorelas de Salas, estará ampliamente ilustrado por notas explicativas, grabados y ejemplos musicales" y elabora un nuevo plan del libro Los villancicos, cantadas y pastorelas de Esteban Salas:

"1.- Advertencia

2.- Introducción

I- Historia de la Capilla de música de la Catedral de Santiago de Cuba

II- Acerca de los Villancicos, Cantadas y Pastorelas de Esteban Salas

a) Antecedentes históricos

b) el texto

c) las voces

d) los instrumentos

e) la tonalidad

f) la forma

g) las fuentes para la investigación

h) conclusiones, capítulo abierto

3.- Los Villancicos, Cantadas y Pastorelas de Esteban Salas (análisis minucioso de cada una de las obras, desde el punto de vista musical; con su texto completo)"13.

La labor de investigación y producción de resultados de Balaguer era intensa, del "año de la planificación" (1962) al "año de la organización" (1963) ${ }^{14}$ varía la propuesta del libro en cuanto a la cantidad de villancicos localizados, de 46 a 51. Además, comprende que ha de contextualizar el desempeño musical de Salas haciendo alusión a la institución para la que desempeñó su cargo: la capilla de música de la Catedral de Santiago de Cuba. Toma en cuenta el análisis del texto,

13 Plan y contenido del libro Los Villancicos, Cantadas y Pastorelas de Esteban Salas presentado a la Comisión de Publicaciones de la Universidad de Oriente por Pablo Hernández Balaguer, Santiago de Cuba, 20 de noviembre de 1963, SUO, exp. s/n.

14 Desde el triunfo de la Revolución de 1959 en Cuba los años reciben nombres distintivos. 
aunque será solo desde el punto de vista literario formal, Balaguer no creía necesario hacer una exégesis del contenido religioso. Así, con esta segunda estructura se conformó su libro, Los villancicos, cantadas y pastorelas de Esteban Salas, que no será publicado hasta 1986, veinte años después de su muerte, por la Editorial Letras Cubanas (Hernández Balaguer 1986b).

\section{LA CAPILLA DE MÚSICA DE LA CATEDRAL DE SANTIAGO DE CUBA}

Directamente derivado de ese texto, el artículo "La Capilla de Música de la Catedral de Santiago de Cuba", que apareció en la Revista Musical Chilena número 90 del año 1964, es su más completo trabajo sobre el tema de Esteban Salas publicado en vida. Para entonces era director de esta publicación Samuel Claro, quien agradeció a Balaguer su "magnífica colaboración"15.

Balaguer aplica ya los estudios contextualizados sobre la historia musical y para ello se coloca desde el siglo XVI. Para esta fecha ya ha hecho el hallazgo del manuscrito que él mismo consideró como el "más antiguo documento de la música cubana” (Hernández Balaguer 1986a: 25-71): el Auto de erección de una capilla de música de 1682 por mandato del obispo Juan García de Palacios que alude al controvertido tema de los ministriles esclavos del Canónigo Don Juan de Cisneros. Ya comenta sobre paralelos entre la situación de Cuba y lo ocurrido en los virreinatos de Nueva España y Perú. Su principal bibliografía de referencia será uno de los artículos publicados en el número 81-82 de la Revista Musical Chilena, el estudio de Andrés Sas sobre "La vida musical en la Catedral de Lima durante la colonia” (pp. 8-53) y el libro Panorama de la música mexicana desde la independencia hasta la actualidad (1941, reed. Cenidim, 1996) de Otto Mayer-Serra. Este texto corresponde íntegramente a la introducción de su libro -al que ya hemos hecho mención- Los villancicos, cantadas y pastorelas de Esteban Salas y así fue publicado en la edición de 1986 (1986b). Revisando la bibliografía citada en el resto de los epígrafes de ese libro encontramos menciones a músicos como Antonio Salazar (Puebla, ca. 1650-México, 1715), Manuel de Sumaya (Ciudad de México, 1680Oaxaca, 1755) y Doménico Zípoli (Prato, 1688-Córdoba, Argentina, 1726) -este último seguramente derivado del trabajo de Lauro Ayestarán aunque no aparece citado. Hay que recordar que la edición de ese texto inédito fue hecha 20 años después de su muerte. La mayoría de sus referencias a los sucesos de la música en el período colonial de América Latina parten de los trabajos contenidos en el referido número 81-82 de la Revista Musical Chilena y hace mención explícita al de Vicente Gesualdo, "La música en Argentina durante el período colonial" (pp. 125-134), al ya citado de Andrés Sas, los dos trabajos de Robert Stevenson, "Música en Quito" (pp. 172-194) y "La música colonial en Colombia” (pp. 153-171), Carlos Vega, "Un códice peruano colonial” (pp. 54-93), a lo que se suman el libro Historia de la música en México de Gabriel Saldívar (1934), el antológico libro de José

15 Carta de Magdalena Vicuña, redactora jefe de la Revista Musical Chilena a Pablo Hernández Balaguer, Santiago de Chile, 2 de julio de 1964, SUO, exp. s/n. 
Subirá sobre Historia de la música española e hispanoamericana (1953) y la consulta a las partituras publicadas por el Archivo de Música Colonial Venezolana. Es así que, aún con las limitaciones de comunicación e intercambio que conllevaba la situación política de Cuba, Balaguer se insertó en la comunidad científica de su época y alcanzó a realizar estudios musicológicos que estuviesen a la altura de lo que hacían sus contemporáneos en la misma materia.

\section{LA INTERPRETACIÓN HISTÓRICA DE LA OBRA DE ESTEBAN SALAS}

Otro hito trascendente fue su relación con Juan Orrego Salas, director del Latin American Music Center, radicado en la Universidad de Indiana, Bloomington, Estados Unidos, quien recomienda a Juana Subercaseaux, codirectora y fundadora del Conjunto de Música Antigua de la Pontificia Universidad Católica de Chile, que escriba a Balaguer para que le envíe música colonial cubana con el propósito de engrosar la colección del Departamento de Música de la Universidad y utilizarlas en una gira del grupo en Europa que tendría lugar en febrero de $1966^{16}$.

Juan Orrego Salas, director del Latin American Music Center, había entrado en contacto con Pablo Hernández Balaguer desde el 22 de marzo de 1963², con motivo de conminarle a enviar la ficha que debía llenar para incluirle -por su faceta de compositor- en el Diccionario biográfico de compositores latinoamericanos ${ }^{18}$. Balaguer envía lo solicitado y además incluye el folleto y el disco de Esteban Salas. En agradecimiento, Orrego Salas le responde con la siguiente misiva:

"Me es muy grato acusar recibo de su envío del disco con obras del compositor cubano Esteban Salas, las que me han parecido de un extraordinario interés y excelentemente sustentadas por el valioso análisis y comentario impreso que incluye. Mis más calurosas felicitaciones. Considero que la grabación y folleto a que me refiero significan una contribución de primera categoría para el conocimiento del pasado musical de Latino América, tan ilustremente representado por Esteban Salas. Deseo aprovechar la oportunidad para consultarle acerca de la existencia de grabaciones y estudios similares sobre las obras de otros compositores cubanos como Ignacio Cervantes, Antonio Raffelín, y Juan Paris. De existir estos materiales me interesaría mucho recibirlos para poder promover interés entre los estudiantes de dos Seminarios que dirijo, por realizar estudios sobre el pasado musical de Cuba"19.

16 Carta de Juana Subercaseaux a Pablo Hernández Balaguer, Santiago de Chile, 2 de marzo de 1965, SUO, exp. s/n. La gira efectivamente se efectuó según consta en la Revista Musical Chilena, XX/97 (julio-septiembre, 1966), pp. 81-84. En p. 83 se hace referencia a una crítica de Alemania que alude a la interpretación por el citado conjunto de un Jubilate de Esteban Salas en versión de canto, flauta y bajo continuo.

17 Carta de Juan Orrego Salas, director del Latin American Music Center de la Indiana University School of Music a Pablo Hernández Balaguer, Bloomington, 22 de marzo de 1963, SUO, exp. s/n.

18 Las bases de datos recopiladas por Orrego Salas sirvieron para la confección del libro de Ricardo Lorenz, Luis R. Hernández y Gerardo Dirié. Scores and Recordings at the Indiana University Latin American Music Center. Bloomington: Indiana University Press, 1995.

19 Carta de Juan Orrego Salas, director del Latin American Music Center de la Indiana University School of Music, a Pablo Hernández Balaguer, Bloomington, 9 de octubre de 1963, SUO, exp. s/n. 
Cada nuevo contacto que Balaguer establecía le permitía avanzar en su propósito de difundir el patrimonio musical cubano para que fuera interpretado y conocido más allá de las fronteras de Cuba. Por eso, luego de su intercambio con Juan Orrego Salas, la relación de Balaguer con Juana Subercaseaux permitió que su conjunto de música antigua fuese el primer portador de la interpretación histórica de la obra de Esteban Salas. Entre la correspondencia personal del musicólogo se conserva una carta de Juana Subercaseaux -viola da gamba del Conjunto de Música Antigua de la Pontificia Universidad Católica de Chile- en la que con fecha 15 de julio de 1965, acusa recibo de las partituras de Salas enviadas por Balaguer, y comenta el uso que haría de ellas:

"Mucho le agradezco su muy gentil carta y el maravilloso paquete de música que Ud. ha tenido la bondad de enviarme y que recibí anoche. Ya he seleccionado dos muy lindos Villancicos de Esteban Salas que tocaremos en Lima en el mes de septiembre, en el Festival de Arte Colonial Latinoamericano, en el cual nos han invitado a hacernos cargo de la parte musical, Esteban Salas estará en la buena compañía de Fructus [sic] del Castillo, Fernando [sic] Franco y Padilla, de México, de Orejón, Torrejón y otros anónimos del Perú, y de música anónima colonial chilena del norte de Chile y de la Isla de Chiloé. Como Ud. ve este será un programa novedoso y de alto interés para todos nosotros los latinoamericanos" 20 .

A partir de este intercambio Balaguer le inquiere acerca de la música colonial de Latinoamérica y sus principales inquietudes se centran en conocer los trabajos que ya han sido publicados sobre músicos contemporáneos con Esteban Salas y de los progresos en la interpretación de música antigua, lo que para esos años se valoraba ya como un importante complemento a la investigación. A sus ansias de saber, Juana Subercaseaux le responde:

"Quiero felicitarlo por la extraordinaria labor que está realizando Ud. al dar vida nuevamente a obras cubanas tan importantes como las que Ud. me ha enviado. En cuanto a lo que Ud. me pide acerca de la información sobre otras fuentes u obras publicadas, solo puedo decirle lo siguiente: acerca de la música colonial mejicana, existe un tomo llamado Tesoro de la Música Polifónica en México, editada [o] por el Dr. Jesús Bal y Gay y presentada [o] por el Instituto Nacional de Bellas Artes de ese país. Por otra parte el Dr. Robert Stevenson ha publicado un valiosísimo libro sobre la música colonial peruana (The music of Peru) impreso por la Unión Panamericana de Washington, en 1960. También el musicólogo, señor André Sas, un belga que vive en Lima desde largos años, ha desenterrado muchos manuscritos de Orejón y Torrejón, contemporáneos de Esteban Salas. [...] En cuanto a la música colonial chilena, esta es extremadamente pobre. Nosotros (cuando digo nosotros me refiero al Conjunto de Música Antigua) hemos usado unas canciones semi-folklóricas de 1545, que se cantaban y bailaban en la festividad de la Virgen de La Tirana, en la provincia de Tarapacá, que era, en realidad en aquella época, parte del Virreynato del Perú. Hemos encontrado

20 Carta de Juana Subercaseaux codirectora y fundadora del Conjunto de Música Antigua de la Pontificia Universidad Católica de Chile a Pablo Hernández Balaguer, Santiago de Chile, 15 de julio de 1965, SUO, exp. s/n. 
también dos villancicos muy curiosos y muy españoles, de la Isla de Chiloé, al sur de Chile, pero ellos nos han llegado sin acompañamiento, por lo cual nosotros hemos debido reconstruirlos. Este material chileno se lo haré llegar cuanto antes".

"Sé que en Quito, en Bogotá y en varias ciudades bolivianas como La Paz, Sucre, Cochabamba y Santa Cruz hay grandes riquezas musicales, pero no he podido establecer los contactos necesarios para conseguirla. Puede ser que con el tiempo, a través de los viajes de nuestro Conjunto, logre establecer contactos personales con gente especializada y seria que me pueda facilitar estas obras [...]".

"Ojalá llegue el día en que pueda conocerlo personalmente y conversar largamente sobre estos temas que nos apasionan a ambos. Me gustaría también que Ud. oiga nuestro Conjunto de Música Antigua interpretando las obras que Ud. me ha enviado como también obras del Medioevo y del Renacimiento europeo, interpretadas en instrumentos de la época, todos ellos extraordinariamente hermosos"21.

Ya Balaguer se había convertido en el hombre de referencia para los estudios sobre la música cubana del período colonial y a 10 de junio de 1966 Magdalena Vicuña, redactora jefe de la Revista Musical Chilena, continuaba enviándole cartas con la solicitud de nuevos trabajos:

“[...] me están haciendo mucha falta sus interesantísimos artículos. El año 1967 quiero dedicarlo a la música de nuestro continente y, por supuesto, deseo tener algún artículo suyo sobre la música en Cuba. Estoy cierta que usted debe tener muchas cosas interesantes que ofrecernos y bien sabe que las páginas de esta revista están a su disposición ¿sobre qué tópico o tópicos querría usted escribirnos? Espero su respuesta con ansias"22.

No habría respuesta, Pablo Hernández Balaguer había muerto el 31 de enero de 1966. Su fallecimiento fue anunciado a la comunidad científica a través de la Revista Musical Chilena en el número 99 de enero-marzo de 1967, p. 113.

\section{Pablo Hernández Balaguer}

En Febrero pasado, se cumplió un año del fallecimiento del ilustre musicólogo e investigador cubano, Pablo Hernández Balaguer. El maestro Hernández Balaguer dedicó sus esfuerzos a investigar el pasado colonial de Cuba y a su pluma se deben estudios definitivos sobre la obra de Esteban Salas y la música en la Catedral de Santiago de Cuba.
Balaguer fue Director del Departamento de Investigaciones de la Universidad de Oriente de Santiago de Cuba. Deja preparadas varias obras y en bocetos muchas otras. La Revista Musical Chilena se aprecia de contar entre sus páginas con dos estudios del desaparecido erudito cubano.

21 Carta de Juana Subercaseaux codirectora y fundadora del Conjunto de Música Antigua de la Pontificia Universidad Católica de Chile a Pablo Hernández Balaguer, Santiago de Chile, 15 de julio de 1965, SUO, exp. s/n.

22 Carta de Magdalena Vicuña, redactora jefe de la Revista Musical Chilena a Pablo Hernández Balaguer, Santiago de Chile, 10 de junio de 1966, SUO, exp. s/n. 
Finalmente la obra de Esteban Salas fue interpretada por vez primera en Cuba en versiones históricas a partir de la creación del Conjunto de Música Antigua Ars Longa fundado por Teresa Paz y Aland López en 1994. Insertado en el espíritu que acompaña la rehabilitación del Centro Histórico de La Habana Vieja que lleva a cabo la Oficina del Historiador de la Ciudad de La Habana, dirigida por el Dr. Eusebio Leal Spengler, este conjunto posee su sede en la antigua iglesia de San Francisco de Paula -templo del siglo XVII restaurado en 2000- en el que la música antigua tiene ahora un espacio exclusivo y donde ocurre el milagro de la vuelta a la vida del más antiguo Patrimonio Musical Cubano, como lo había querido Odilio Urfé.

Inspirados en el modelo de Pablo Hernández Balaguer, la secuencia de acontecimientos que se enumeran: localización, catalogación, transcripción, interpretación, publicación y grabación son la base del plan de trabajo que sigue hoy el Gabinete de Patrimonio Musical Esteban Salas para obtener las conclusiones más cercanas a la realidad histórica y la realización artística. Partiendo de este presupuesto, el provechoso intercambio entre interpretación e investigación ha dado como fruto la preparación de múltiples conciertos presentados en importantes escenarios nacionales e internacionales, la coordinación de once Festivales de Música Antigua, la publicación en ocho volúmenes de la colección Música Sacra de Cuba, siglo XVIII y la grabación de tres discos dedicados a la obra de Esteban Salas en estrecha relación con la obra publicada de este autor.

Pablo Hernández Balaguer, el joven investigador que tanta responsabilidad tuvo en la decisión sobre el más antiguo patrimonio musical cubano, fue asesorado por dos grandes intelectuales de su época: Odilio Urfé y Argeliers León. En solo diez años de intensa labor Balaguer logró publicar partituras y artículos relativos a la música del período colonial en Cuba, crear un archivo de música y divulgar fuera de las fronteras insulares sus resultados, en esos convulsos años sesenta en los que Cuba era relegada del mundo. Dos artículos suyos fueron publicados en la Revista Musical Chilena, junto a los más grandes investigadores de su época, en la publicación más conocida en el ámbito latinoamericano en esos años. Y a su vez fue la Revista Musical Chilena el medio que le permitió conocer los estudios de sus contemporáneos en una época en la que ya Robert Stevenson había publicado su Music in Mexico (1952) y The Music of Peru (1960), Lauro Ayestarán el primero y único volumen de La música en el Uruguay (1953), José Ignacio Perdomo Escobar la tercera edición de su Historia de la música en Colombia (1963) o Eugenio Pereira Salas Los orígenes del arte musical en Chile (1941) y la Historia de la música en Chile (1850-1900) (1957), por solo mencionar algunos de los textos más representativos. Fue su gestión la que permitió la primera inserción de la obra de Esteban Salas como parte del movimiento de música antigua liderado por el Conjunto de la Pontificia Universidad Católica de Chile y su difusión en escenarios de Latinoamérica y Europa en los que la música de Salas sonó por fin junto a la de sus colegas de Latinoamérica. 


\section{BIBLIOGRAFÍA}

La presente bibliografía se circunscribe a los escritos de Pablo Hernández Balaguer y a las publicaciones que guardan una relación directa con ellos. Las restantes publicaciones se indican en el texto del trabajo.

Carpentier, Alejo

1989 La música en Cuba. La Habana: Editorial Pueblo y Educación.

Gómez Cairo, Jesús

1989 "De paciencia y pasiones. El Seminario de la Música popular cumple 40 años", Revista Clave, $\mathrm{N}^{\circ} .14$ (julio-septiembre), pp. 7-10. La Habana.

Hernández Balaguer, Pablo

1959 "Necesidad de un archivo nacional de música”. Periódico Revolución (27 de abril de 1959). La Habana. En Hernández Balaguer 1986a:215-219.

1960a Obras de Esteban Salas y un ensayo de Pablo Hernández Balaguer. Santiago de Cuba: Universidad de Oriente, Departamento de Actividades Culturales, Escuela de Música.

1960b "En torno a los villancicos de Esteban Salas". Revista de Música de la Biblioteca Nacional, 1/2, pp. 44-55.

1961a Catálogo de música de los archivos de la Catedral de Santiago de Cuba y del Museo Bacardí. La Habana: Biblioteca Nacional José Martí.

1961b Esteban Salas. Claras luces. Villancico de Navidad a cuatro voces con violines y bajo. Santiago de Cuba: edición facsimilar, Departamento de Actividades Culturales, Universidad de Oriente.

1961c Esteban Salas. Cuatro villancicos. La Habana, Ediciones del Departamento de Música de la Biblioteca Nacional José Martí.

1961d "Esteban Salas. Apuntes sobre su época y su obra”, Periódico Sierra Maestra (10 de septiembre), pp. 3-5. Santiago de Cuba.

1961e Cratilio Guerra. Misa en do mayor para tres voces y orquesta. Santiago de Cuba: Universidad de Oriente.

$1961 f$ Silvano Boudet. Primera lección de difuntos. Santiago de Cuba: edición facsimilar, Consejo Provincial de Cultura.

1962a "Panorama de la música colonial cubana”, Revista Musical Chilena, XVI/81-82 (julio-diciembre), pp. 201-208. Santiago de Chile.

1962b 3 obras litúrgicas. Santiago de Cuba: Universidad de Oriente.

1964a "La Capilla de Música de la Catedral de Santiago de Cuba", Revista Musical Chilena, XVIII/90 (octubre-diciembre), pp. 14-61. Santiago de Chile.

1964b Breve historia de la música cubana. Santiago de Cuba: Universidad de Oriente.

1979 Catálogo de los archivos de la Catedral de Santiago de Cuba y del Museo Bacardí. Santiago de Cuba: Editorial Oriente.

1986a El más antiguo documento de la música cubana y otros ensayos. La Habana: Editorial Letras Cubanas. 
1986b Los villancicos, cantadas y pastorelas de Esteban Salas. La Habana: Editorial Letras Cubanas.

Orovio, Helio

1981 Diccionario de la música cubana: biográfico y técnico. La Habana: Editorial Letras Cubanas.

Pérez González, Juliana

2004 Génesis de los estudios sobre música colonial hispanoamericana: un esbozo historiográfico. Ministerio de Cultura. http://redalyc.uaemex.mx/src/inicio/ArtPdfRed. jsp?iCve $=83300909$.

\section{Documentos consultados}

- Correspondencia inédita remitida a Pablo Hernández Balaguer. Formó parte de la documentación del antiguo Departamento de Investigación y Extensión Musical y hoy se conserva en la Sección de Extensión Universitaria de la Universidad de Oriente, Santiago de Cuba, sin clasificar. Para el presente trabajo hemos consultado 58 cartas fechadas entre el 27 de septiembre de 1955 y el 10 de junio de 1966. 